\title{
Different therapeutic modalities for aortic arch disease combined with Kommerell's diverticulum: single-center experience with nine cases
}

\author{
Yi Chang, Cun-Tao Yu, Hong-Wei Guo, Xiao-Gang Sun, Qian Chang, Xiang-Yang Qian \\ Department of Vascular Surgery, Fuwai Hospital, Cardiovascular Institute, Chinese Academy of Medical Science \& Peking Union Medical College, \\ Beijing, China \\ Contributions: (I) Conception and design: All authors; (II) Administrative support: XY Qian, CT Yu, Q Chang; (III) Provision of study materials or \\ patients: CT Yu, HW Guo, XG Sun, Q Chang; (IV) Collection and assembly of data: Y Chang; (V) Data analysis and interpretation: Y Chang, XY \\ Qian; (VI) Manuscript writing: All authors; (VII) Final approval of manuscript: All authors. \\ Correspondence to: Xiang-Yang Qian. Department of Vascular Surgery, Fuwai Hospital, Cardiovascular Institute, Chinese Academy of Medical Science \\ \& Peking Union Medical College, No. 167 North Lishi Road, Xicheng District, Beijing, China. Email: m13701097213@163.com.
}

\begin{abstract}
Background: Aortic arch disease with Kommerell's diverticulum is an uncommon but troublesome condition, and there are a variety of therapeutic modalities for treating this. We retrospectively analyzed cases who underwent open surgery to summarize different situations and approaches.

Methods: From November 2015 to January 2019, nine patients underwent operation for the mentioned disorder. Four patients with aortic dissection received total arch replacement. Two patients suffering from type B aortic dissection (TBAD) have accepted graft replacement from ascending aorta (aAO) to descending aorta. Two patients with true aneurysm and congenital malformation underwent graft bypass from aAO to descending aorta. One patient had graft replacement of descending aorta.

Results: There were nine (eight males and one female) patients with median age of 45 (from 14 to 54) years. The 30 -day mortality was $11.1 \%$ (1 patient) due to refractory respiratory failure caused by compression of bronchus. One patient had complication of peripheral neuropathy and recovered eventually. Eight patients were followed-up for a median period of 20 [9-46] months. All patients were alive and had no long-term complications except one patient who received re-intervention due to delayed dilation of downstream aorta.

Conclusions: Treatment for different arch lesions with Kommerell's diverticulum should follow corresponding indications. Open surgery is the preferred choice and detailed therapeutic strategy depends on the extension of aneurysm, classification and phase of dissection. Stenting might cause airway compression when right-sided arch and vascular ring exist.
\end{abstract}

Keywords: Aortic arch; aneurysm; Kommerell diverticulum (KD); aberrant subclavian artery (ASA); therapeutic modalities

Submitted Apr 07, 2020. Accepted for publication Jul 25, 2020.

doi: $10.21037 /$ jtd-20-1602

View this article at: http://dx.doi.org/10.21037/jtd-20-1602

\section{Introduction}

Aortic arch disease combined with Kommerell's diverticulum is a rare but problematic condition. The distinct arch configuration and supra-arch vessel distribution are the main differences from other types and is critical to deal with Kommerell's diverticulum. It is primarily defined as the dilation of initial segment of aberrant subclavian artery (ASA) (1). Several types of arch locations and corresponding supra-arch arteries arrangements were described in the literatures (2-4). There are different therapeutic modalities 


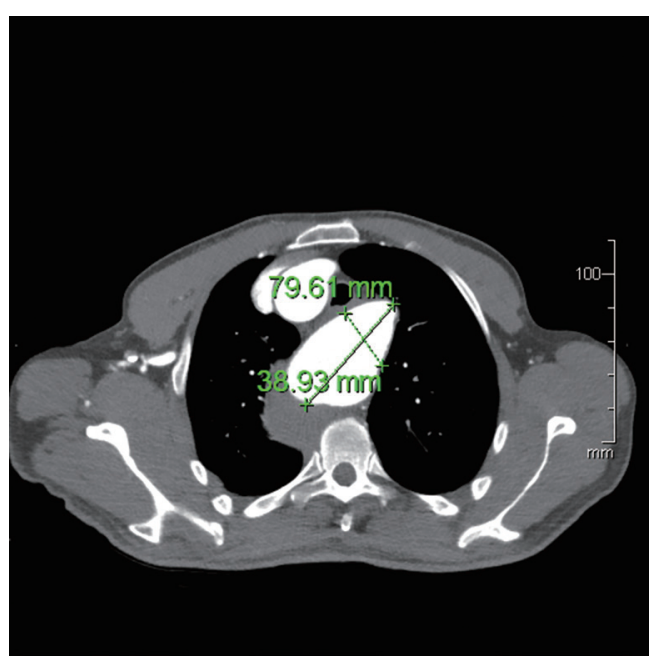

Figure 1 The diameter of diverticulum orifice and maximum diameter of DTA nearby diverticulum measured on CT scan. DTA, descending thoracic aorta; CT, computed tomography.

and so the paradigm used for treatment in our center in the recent 4 years was summarized and discussed. We present the following article in accordance with the STROBE reporting checklist (available at http://dx.doi.org/10.21037/ jtd-20-1602).

\section{Methods}

The clinical data of patients diagnosed with aortic arch disease and Kommerell's diverticulum and those who underwent operation in our hospital from 2015 to 2019 were retrospectively analyzed. The study was conducted in accordance with the Declaration of Helsinki (as revised in 2013). The study was approved by institutional ethics committee (No. 2018-1094) and informed consent was taken from all the patients. A total of nine patients were included. Kommerell's diverticulum was diagnosed according to the criteria proposed by previous study (3). The aortic arch is considered hypoplastic if the diameter is less than $50 \%$ than that of the ascending aorta (aAO). The sequence of supra-arch arteries arising from the rightsided aortic arch was found in seven patients, which was as follows: left common carotid artery (LCCA), right common carotid artery (RCCA), right subclavian artery (RSA) and aberrant left subclavian artery (ALSA). And the sequence corresponding to left-sided aortic arch in two patients was RCCA-LCCA-left subclavian artery (LSA)-aberrant right subclavian artery (ARSA). Five patients had chest pain and back pain, while the remaining had no symptoms.

The indication of operation for true aneurysm in our center was considered by two aspects: the symptom and the size. The patient with the symptom of tracheal or/and esophageal compression requires operation. If the patient had no symptom, then the aortic arch requires replacement when its diameter was more than $50 \mathrm{~mm}$. When the diameter of the diverticular orifice was more than $30 \mathrm{~mm}$ or the maximum diameter of descending thoracic aorta (DTA) near the diverticulum was more than $50 \mathrm{~mm}$, then DTA interference is required. The method of measuring the diverticulum and DTA was shown in Figure 1. The general data of all patients was demonstrated in Table 1 .

Due to different types and extent of lesions, all the nine patients received different operations, which were described as follows:

The first four patients had aortic arch replacement through median sternotomy with different stent implantations into the DTA. Femoral artery was selected in these patients as the initial cannulation site and the right atrial cannulation was used routinely to establish cardiopulmonary bypass (CPB). Hypothermia cardiac arrest (HCA) and selective cerebral perfusion (SCP) were used for open distal anastomosis. The lowest nasopharyngeal temperature should be $25^{\circ} \mathrm{C}$ and SCP was achieved by extra LCCA cannulation with a flow rate of $5-10 \mathrm{~mL} / \mathrm{kg} / \mathrm{min}$.

For patients 5 and 6, double incisions (median and lateral thoracotomies) and "arch first" techniques described by Kouchoukos previously (5) were used for graft replacement from aAO to DTA. aAO was initially selected for cannulation. A 4-branched vascular graft was filled with blood by cannulating and perfusing one of the branches and clamping other outlets of the graft. Debranching of supraarch arteries was finished by other branches of the graft. The DTA was then clamped and sewn with one end of the graft which was delivered to pleural cavity through median incision. Finally, the aAO was resected and its proximal stump was anastomosed with the graft after cardioplegia injection.

For patient 7 , intracardiac operation was performed through median thoracotomy. The distal arch and the upper DTA (till level 6 of the thoracic vertebral body) were replaced with straight graft by clamping and sewing through left thoracotomy.

For patients 8 and 9, clamping of the distal arch to resect the coarctation remained difficult, and so a bypass from aAO to DTA was made through double incisions. The distal DTA was clamped and anastomosed with a 
Table 1 General data of patients

\begin{tabular}{|c|c|c|c|c|c|c|c|c|}
\hline No. & Age & Etiology & Extension & Initial tear & $\begin{array}{l}\text { Arch } \\
\text { side }\end{array}$ & Operation & Approach & $\begin{array}{l}\text { Reconstruction of } \\
\text { supra-arch arteries }\end{array}$ \\
\hline 1 & 40 & Chronic TAAD & Entire aorta & $\mathrm{aAO}$ & $\mathrm{R}$ & $\begin{array}{l}\text { Bentall + arch } \\
\text { replacement + FET }\end{array}$ & Median & 4 branches \\
\hline 2 & 33 & Acute TAAD & Entire aorta & Distal arch & $\mathrm{L}$ & $\begin{array}{l}\mathrm{aAO}+\text { arch } \\
\text { replacement + FET }\end{array}$ & Median & 4 branches \\
\hline 4 & 49 & Acute TBAD & Total arch + DTA & Orifice of KD & $\mathrm{R}$ & $\begin{array}{l}\mathrm{aAO}+\text { arch } \\
\text { replacement + TEVAR }\end{array}$ & Median & 4 branches \\
\hline 5 & 45 & Chronic TBAD & Total arch + DTA & Orifice of KD & $\mathrm{R}$ & $\begin{array}{l}\text { aAO + arch + DTA } \\
\text { replacement }\end{array}$ & Median + right & 4 branches \\
\hline 8 & 14 & $\begin{array}{l}\text { Aneurysm and } \\
\text { arch hypoplasia }\end{array}$ & DTA & - & $\mathrm{R}$ & aAO-DTA bypass & Median + left & ALSA, RSA \\
\hline 9 & 53 & $\begin{array}{l}\text { Aneurysm and } \\
\text { COA }\end{array}$ & DTA & - & $\mathrm{R}$ & aAO-DTA bypass & Median + right & ALSA \\
\hline
\end{tabular}

TAAD, type A aortic dissection; TBAD, type B aortic dissection; IE, infective endocarditis; Al, aortic insufficiency; MI, mitral insufficiency; COA, coarctation of aorta; DTA, descending thoracic aorta; aAO, ascending aorta; KD, Kommerell diverticulum; FET, frozen elephant trunk; TEVAR, thoracic endovascular aortic repair; AVR, aortic valve replacement; MVR, mitral valve replacement; ALSA, aberrant left subclavian artery; RSA, right subclavian artery; ARSA, aberrant right subclavian artery.

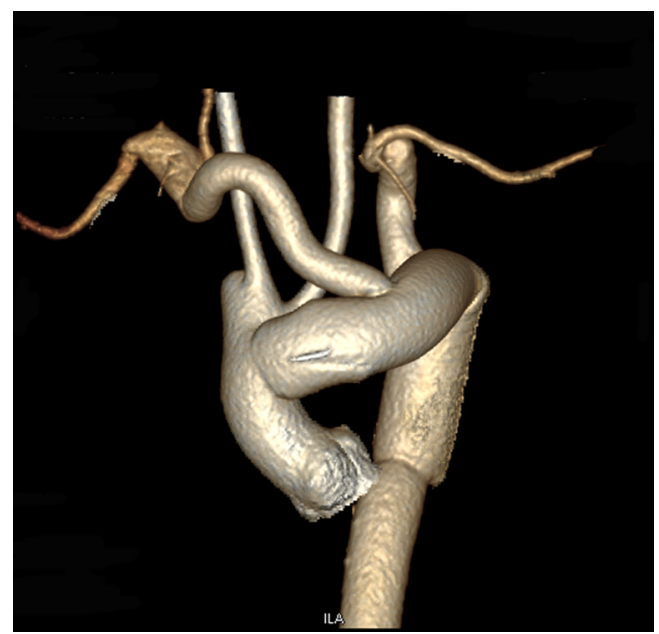

Figure 2 CT three-dimensional reconstruction image of a bypass of graft from aAO to DTA with the proximal DTA resected and the distal arch closed by suturing. CT, computed tomography; aAO, ascending aorta; DTA, descending thoracic aorta. straight graft initially in both the patients. The proximal DTA was resected and the distal arch was closed by continuous suturing. The proximal end of the graft was then anastomosed with aAO by end-to-side anastomosis. The image of bypass from aAO to DTA using computed tomography (CT) three-dimensional reconstruction was shown in Figure 2.

For the first six patients, all the supra-arch arteries were reconstructed, and the last three patients underwent ASA reconstruction in the chest. Patient 9 has accepted RSA reconstruction due to right subclavian aneurysm.

\section{Results}

The median age of the patients (eight males and one female) was 45 (from 14 to 54) years. The mean CPB time was $169.9 \pm 84.1[142-253]$ minutes. The mean duration of myocardial ischemia was $73.0 \pm 41.9[17-133]$ minutes. The median HCA time was 18 [13-28] minutes. The median 
mechanical ventilation time and ICU stay was 29 [6485] hours and 4 [1-27] days. The 30-day mortality was $11.1 \%$ (1 patient). Patient 4 died due to refractory respiratory and circulatory failure on day 17 because of crippling bronchial compression found by bronchofibroscope after re-intubation. Patient 5 had myasthenia of limbs and respiratory muscle postoperatively and was depended on mechanical ventilation. Critical illness polyneuropathy was confirmed by a neurologist who suggested neurotrophic treatment. He successfully detached from the respirator after 485 hours.

Patient 3 had dry cough and gained remission 1 week later. A slight compression of tracheal carina was observed on CT scan.

Eight patients were alive with a median follow-up duration of 20 [9-46] months. Patient 1 received reintervention by thoracic endovascular aortic repair (TEVAR) due to dilation of downstream aorta beyond frozen elephant trunk (FET) 6 months later successfully. No long-term complications were found in the remaining seven patients.

\section{Discussion}

ASA is an uncommon vascular anomaly and Kommerell's diverticulum has an uncertain natural course of disease $(6,7)$. From our cases, it is shown that the aortic arch lesion associated with Kommerell's diverticulum occurred in different scenarios: dissection, aneurysm or coarctation of aorta (COA). The therapeutic strategies differed in different situations. For patient with aortic aneurysm, the symptom and size of the aneurysm should be initially assessed. The patient with symptom of tracheal or/ and esophageal compression requires operation. If the patient had no symptom, the indication for surgery was controversial. Cinà et al. (8) have suggested that when the diameter of diverticular orifice is more than $30 \mathrm{~mm}$, then the patient should accept operation. Ota et al. (9) have suggested that when the maximum diameter of DTA near the diverticulum is more than $50 \mathrm{~mm}$, then the patient should accept operation. We followed the above instructions and replaced aortic arch when the diameter of the arch was more than $50 \mathrm{~mm}$.

In our study, there were more cases who suffered from aortic dissection. As reported in the literature (6,9-11), patients with acute aortic dissection involving entire arch should accept emergency operation and total arch replacement regardless of classification. In our center, these patients were treated in the similar way with total arch replacement plus FET or endovascular stent or both. Although TEVAR could be an appropriate choice for type B aortic dissection (TBAD) coupled with Kommerell diverticulum (KD) (12-15), open surgery could not be abandoned $(11,16)$. The indication of operation for chronic aortic dissection remained the same as that of true aneurysm and graft replacement was considered as a better choice in our opinion. The replacement of DTA might be considered as a better choice if only distal arch was involved by dissection.

A more extensive arch replacement for aortic dissection involving entire arch was recommended in order to achieve better long-term results but the importance of dealing with Kommerell's diverticulum accurately should be considered. Isolation of diverticulum by stent graft was preferred and how to select the stent depends on the location of initial tear and size of $\mathrm{KD}$. A proximal intimal tear from aAO or arch and a small diverticulum indicated that FET is enough. But a distally located intimal tear from DTA and a larger orifice of the diverticulum (more than $30 \mathrm{~mm}$ ) are difficult for occlusion by single FET. So, another endovascular stent graft anchoring to FET or a single longer FET with a length of $150 \mathrm{~mm}$ or more is warranted $(6,10,17)$.

A vascular ring surrounding the trachea and esophagus is formed by ALSA and ligamentum arteriosum when the arch is right-sided. The structures inside the vascular ring might be compressed by the dilation of diverticulum. Delivering of FET or endovascular stent graft might still worsen the condition. As mentioned above, patient 4 was considered as an unsuccessful case due to lethal airway compression caused by inappropriate stenting. Patient 3 also had compression of trachea after FET and endovascular stent graft implantation. Maybe a soft elephant trunk continued by stent grafting is the preferred choice in such patients. TEVAR as a re-intervention following FET in the first operation was reported by van Bogerijen and colleagues (18). In our study, patient 1 had false lumen dilation of downstream DTA due to secondary tears after single FET implantation and TEVAR has successfully isolated the lesions.

We believed that arch hypoplasia and coarctation of the aorta have no concern with KD in the last two cases and the two types of problems should be solved simultaneously. Median incisions were made for the convenience of proximal anastomosis.

It is worth mentioning that ASA should be reconstructed directly or through an extra subclavian incision with vertebral artery being reserved. The complication of 
sacrificing the subclavian artery has been reported in other study (19). We believed that reservation of blood supply from the reconstructed subclavian artery prevents paraplegia, especially when long stent is used.

\section{Limitation}

Our study is only a summary of experiences from varied cases. More experiences are warranted to improve the choice of therapeutic strategies.

\section{Conclusions}

Treatment of arch lesions associated with Kommerell's diverticulum should follow corresponding indications and instructions. Open surgery is the preferred choice and detailed therapeutic strategy depends on the extension of aneurysm, classification and stage of dissection. For patients with right-sided arch and larger Kommerell's diverticulum, airway is prone to compression when FET or endovascular stent is used, and so elephant trunk for landing zone or graft replacement might be a better choice for these. ASA requires reconstruction.

\section{Acknowledgments}

Funding: This study was supported by Beijing Municipal Science \& Technology Commission (No. Z181100001718166).

\section{Footnote}

Reporting Checklist: The authors have completed the STROBE reporting checklist. Available at http://dx.doi. org/10.21037/jtd-20-1602

Data Sharing Statement: Available at http://dx.doi. org/10.21037/jtd-20-1602

Conflicts of Interest: All authors have completed the ICMJE uniform disclosure form (available at http://dx.doi. org/10.21037/jtd-20-1602). The authors have no conflicts of interest to declare.

Ethical Statement: The authors are accountable for all aspects of the work in ensuring that questions related to the accuracy or integrity of any part of the work are appropriately investigated and resolved. The study was conducted in accordance with the Declaration of Helsinki (as revised in 2013). The study was approved by institutional ethics committee (No. 2018-1094) and informed consent was taken from all the patients.

Open Access Statement: This is an Open Access article distributed in accordance with the Creative Commons Attribution-NonCommercial-NoDerivs 4.0 International License (CC BY-NC-ND 4.0), which permits the noncommercial replication and distribution of the article with the strict proviso that no changes or edits are made and the original work is properly cited (including links to both the formal publication through the relevant DOI and the license). See: https://creativecommons.org/licenses/by-nc-nd/4.0/.

\section{References}

1. van Son JA, Konstantinov IE. Burckhard F. Kommerell and Kommerell's diverticulum. Tex Heart Inst $\mathbf{J}$ 2002;29:109-12.

2. Guzman ED, Eagleton MJ. Aortic dissection in the presence of an aberrant right subclavian artery. Ann Vasc Surg 2012;26:860.e13-8.

3. Yang C, Shu C, Li M, et al. Aberrant subclavian artery pathologies and Kommerell's diverticulum: a review and analysis of published endovascular/hybrid treatment options. J Endovasc Ther 2012;19:373-82.

4. Freed K, Low VH. The aberrant subclavian artery. AJR Am J Roentgenol 1997;168:481-4.

5. Kouchoukos NT, Blackstone EH, Doty DB, et al. Cardiac Surgery. 3rd ed. Philadelphia: Churchill Livingstone, 2003:1875-7.

6. Austin EH, Wolfe WG. Aneurysm of aberrant subclavian artery with a review of the literature. J Vasc Surg 1985;2:571-7.

7. Idrees J, Keshavamurthy S, Subramanian S, et al. Hybrid repair of Kommerell diverticulum. J Thorac Cardiovasc Surg 2014;147:973-6.

8. Cinà CS, Althani $\mathrm{H}$, Pasenau J, et al. Kommerell's diverticulum and right-sided aortic arch: a cohort study and review of the literature. J Vasc Surg 2004;39:131-9.

9. Ota T, Okada K, Takanashi S, et al. Surgical treatment for Kommerell's diverticulum. J Thorac Cardiovasc Surg 2006;131:574-8.

10. Doi T, Sakata K, Gyoten T, et al. Two-stage hybrid repair in a patient with acute type A aortic dissection associated with right aortic arch with aberrant left subclavian artery originating from a Kommerell diverticulum. Ann Vasc Dis 
2016;9:223-7.

11. Barr JG, Sepehripour AH, Jarral OA, et al. A review of the surgical management of right-sided aortic arch aneurysms. Interact Cardiovasc Thorac Surg 2016;23:156-62.

12. Yuan $Y$, Zhao Y, Zhang M, et al. Endovascular repair of thoracic aortic dissection associated with right-sided aortic arch: report of four cases. J Biomed Res 2016;31:74-8.

13. Follis F, Filippone G, Montalbano G, et al. Repair of postdissection descending thoracic aneurysm with rightsided aortic arch and aberrant left subclavian artery. J Thorac Cardiovasc Surg 2010;139:1086-7.

14. Zhou W. Endovascular repair of a type B aortic dissection with a right-sided aortic arch: case report. J Cardiothorac Surg 2013;8:18.

15. Croccia MG, Levantino M, Cioni R, et al. Endovascular stenting for type B dissection involving a right-sided aortic arch. Interact Cardiovasc Thorac Surg 2012;15:304-6.

16. Tanaka A, Milner R, Ota T. Kommerell's diverticulum in the current era: a comprehensive review. Gen Thorac Cardiovasc Surg 2015;63:245-59.

17. Tanaka K, Tanaka K, Natsume K, et al. Successful surgical exclusion of rapidly expanding kommerell diverticulum following a total arch replacement for an acute type a aortic dissection. Ann Vasc Dis 2014;7:339-42.

18. van Bogerijen GH, Patel HJ, Eliason JL, et al. Evolution in the management of aberrant subclavian arteries and related Kommerell diverticulum. Ann Thorac Surg 2015;100:47-53.

19. Bailey CP, Hirose T, Alba J. Re-establishment of the continuity of the anomalous right subclavian artery after operation for dysphagia lusoria. Angiology 1965;16:509-13.
Cite this article as: Chang $\mathrm{Y}, \mathrm{Yu} \mathrm{CT}$, Guo HW, Sun XG, Chang Q, Qian XY. Different therapeutic modalities for aortic arch disease combined with Kommerell's diverticulum: singlecenter experience with nine cases. J Thorac Dis 2020;12(9):47114716. doi: $10.21037 /$ jtd-20-1602 